\title{
LA RESPONSABILIDAD DE LA CIENCIA EN LA CATÁSTROFE AMBIENTAL
}

\author{
Luis Tamayo ${ }^{1}$ \\ Centro de Investigación y Docencia en Humanidades \\ Estado de Morelos, México
}

Resumen.- En este ensayo se estudia la catástrofe ambiental derivada del cambio climático y el agotamiento de los recursos naturales así como la responsabilidad de la ciencia y la tecnología en su producción. Al final se plantean algunas alternativas de mitigación.

Palabras clave: principio de responsabilidad, ciencia, catástrofe ambiental

Abstract.- This essay studies the environmental catastrophe produced by climate change and the depleted of natural resources, also studies the responsibility of science and technology in his generation. At the end we propose some alternatives of mitigation.

Keywords: imperative of responsibility, science, environmental catastrophe

Decía Antístenes [el discípulo de Sócrates] que Zeus había castigado tan cruelmente a Prometeo porque al entregarles el fuego y la técnica había introducido en los hombres los gérmenes de la lujuria y la corrupción. [Jean Brun $\left.^{2}\right]$

Obra de tal modo que los efectos de tu acción sean compatibles con la permanencia de una vida humana auténtica en la tierra. [Hans Jonas ${ }^{3}$ ]

\section{Introducción}

La humanidad ha generado una crisis ambiental sin precedentes y la responsabilidad de la ciencia y la tecnología en ella es simplemente enorme.

Los humanistas permitimos que muchos de nuestros científicos y tecnólogos se formasen careciendo de los más elementales fundamentos filosóficos. Es por ello que desconocen, tal y como plantea Heidegger desde $1927,{ }^{4}$ que el otro y el mundo no nos son ajenos sino consustanciales. El sentido común, ese que comparte la escisión sujeto-objeto del método científico también común,

\footnotetext{
${ }^{1}$ Doctor en Filosofía por la UNAM, miembro de la Asociación Filosófica Mexicana, la Unión de Científicos Comprometidos con la Sociedad y la Martin Heidegger Gesellschaft. Actualmente es Director de la Unidad de Investigación del Centro de Investigación y Docencia en Humanidades del Estado de Morelos, México.

2 "Los socráticos" en Historia de la filosofía, Vol II, Siglo XXI, México, 1992, p. 260s.

${ }^{3}$ El principio de responsabilidad: ensayo de una ética para la civilización tecnológica, Herder, Madrid, 1995.

${ }^{4}$ Cfr. las tesis, incluidas en Sein und Zeit (Ser y tiempo), sobre los existenciarios Mitsein e Inder-Welt-sein (vide infra, n. 32).
} 
desconoce tal principio ontológico y actúa como si el otro y el mundo le fuesen ajenos.

Las consecuencias de ello, con el paso de los años, se han revelado catastróficas: muchos de nuestros científicos y tecnólogos nunca se preguntan acerca de los efectos que acarreará a la naturaleza producir tal o cual compuesto, establecer tal o cual procedimiento industrial o que producirá tal o cual artefacto. ${ }^{5}$

Y como la ciencia opera según las leyes de Gabor los problemas se magnifican. ${ }^{6}$

Como consecuencia, el mundo se cubre de una cantidad creciente de monstruos, del gas mostaza a la bomba atómica, del unicel a las dioxinas, ${ }^{7}$ de los pesticidas y herbicidas inorgánicos a los Organismos Genéticamente Modificados, de los contaminantes procedimientos para extraer petróleo a los aún peores de las grandes mineras de oro y plata modernas. Nuestra naturaleza se ha convertido en un depósito de cantidades cada vez mayores de productos que los ecosistemas no pueden digerir, enfermando prácticamente a todas las especies de la tierra.

Muchos de nuestros científicos y tecnólogos se volvieron cómplices de la destrucción del mundo orquestada por las grandes corporaciones ecocidas, esas que no se preocupan de la humanidad (pues no forman parte de ella) sino solamente por generar ganancias a sus inhumanos accionistas.

Las corporaciones florecen donde el neoliberalismo se impone, dominando no sólo el mercado, sino la vida de los hombres. El neoliberalismo hace a tales corporaciones hiperpotentes y, a pesar de ello, son ciegas, pues generalmente carecen de visión de largo plazo. Ello es así pues la ganancia económica (su razón de ser) raramente es de largo plazo.

Y dividen al mundo en pobres (la enorme mayoría de los humanos) y ricos (los dueños y accionistas de las corporaciones), incrementando la desigualdad. El medioambiente también se deteriora por el agotamiento acelerado de los productos de la tierra, de los energéticos a los minerales, de los bosques a las selvas y manglares, del agua limpia de los ríos y lagos a la belleza prístina de los glaciares y arrecifes de coral.

\footnotetext{
${ }^{5}$ With nearly 80,000 chemicals on the market in the United States, many of which are used by millions of Americans in their daily lives and are un- or understudied and largely unregulated, exposure to potential environmental carcinogens is widespread. Only a few hundred of the more than $\mathbf{8 0 , 0 0 0}$ chemicals in use in the United States have been tested for safety". "Many known or suspected carcinogens are completely unregulated". Cfr. Leffall, L.; Kripke, M., President's Cancer Panel Annual Report 2008-2009, Reducing environmental Cancer Risk, US Department of Health and Human Services, april 2010, p. ii.

${ }^{6}$ Recordemos que Dennis Gabor (Dr. en Física, ganador del Nobel en 1971 por sus estudios sobre holografía) señaló las leyes básicas del mundo de la técnica :

Primera ley: "Todo lo que sea susceptible de ser descubierto lo será".

Segunda ley: "Todo lo que ha sido descubierto será puesto en práctica al menos una vez" (desde la bomba atómica hasta los peores monstruos biológicos, etc). Cfr. Gabor, D., The mature society, Praeger, New York, 1972.

${ }^{7}$ Nombre como se conoce habitualmente la tetraclorodibenzodioxina.
} 
$\mathrm{Y}$, en tal proceso, hasta los nombres se modifican: la madre tierra se convierte en "sustrato"; las especies hermanas que no son aprovechables por la industria son consideradas cosas inútiles y por ende soslayables.

Muchos de los científicos y tecnólogos que colaboraron con las principales corporaciones del mundo consideran que nada tuvieron que ver con la destrucción del planeta cuando desde el principio carecieron del principio de responsabilidad por cometer el enorme error de participar en corporaciones que también consideraban al otro y al mundo como ajenos.

Y el resto de los ciudadanos nos hacemos cómplices de tal error al consumir los degradados productos que tales corporaciones ofertan.

Y, como consecuencia de todo ello, la humanidad es colocada ante una amenaza de dimensiones nunca antes vista: la catástrofe ambiental derivada del calentamiento global y el agotamiento de los recursos naturales.

\section{Una crisis agravada por el calentamiento global}

El pico del petróleo global tiene la capacidad de sacudir - si no destruir - los fundamentos de la economía industrial global y la cultura. El calentamiento climático global tiene la capacidad de transformar la biosfera más radicalmente que la última era de hielo. Juntas, limitan nuestra capacidad para ofrecer opciones efectivas para responder a una o la otra. El inicio simultáneo del calentamiento global y el pico del suministro global de petróleo representa un reto sin precedentes para la civilización humana.

David Holmgren ${ }^{8}$

En la actualidad la humanidad ha comenzado a sufrir las consecuencias de más de un siglo de depredación sin freno. Los investigadores del IPCC ${ }^{9}$ han indicado que los gases de efecto invernadero, producto no sólo del metabolismo de la vida sino de nuestras industrias, automotores, ganado y plantas generadoras de electricidad, han aumentado la temperatura de la tierra casi en un grado centígrado respecto a la época preindustrial, todo lo cual conduce a un incremento y agravación de los fenómenos hidrometeorológicos (sequías, trombas, huracanes, inundaciones, incendios forestales, ondas de calor) y nos coloca, si el incremento alcanza los $6{ }^{\circ} \mathrm{C}$, en un escenario de extinción masiva.

El incremento de la temperatura, al derretir polos y glaciares, no sólo acidifica y eleva el nivel de los mares, ${ }^{10}$ también afecta a los suelos y disminuye su fertilidad, lo cual conducirá a una crisis alimentaria mundial. La deforestación

\footnotetext{
8 Holmgren, D., "Integrating Climate Change and Peak Oil Scenarios", Energy bulletin, November 2006, p. 1.

${ }_{9}^{9}$ Informe 2007 del Panel Intergubernamental sobre Cambio Climático (IPCC).

${ }^{10}$ National Geographic, april, 2011.
} 
que la humanidad realizó, y aún realiza a lo largo y ancho de la tierra, ${ }^{11}$ acaba con la fuente de donde se recargan las aguas subterráneas que nutren nuestros pozos. En la edición de enero 2011 de National Geographic, Robert Kunzig nos hace notar que la humanidad alcanzará este año los 7 mil millones de seres humanos en la tierra y si pensamos en que hace apenas cien años la humanidad no alcanzaba siquiera los 2 mil millones podemos apreciar que nos encontramos ante un fenómeno descrito por Paul Ehrlich como "explosión demográfica" ${ }^{12}$ La "revolución verde", esa que llenó de fertilizantes, herbicidas y pesticidas inorgánicos el planeta, permitió a buena parte de la población humana vencer la hambruna que, luego de la Segunda guerra mundial, se dibujaba en el panorama, pero dicha "revolución verde" ha generando una terrible dependencia a unos agroquímicos cada vez más onerosos e ineficaces. En abril del 2010 informó el President's Cancer Panel dirigido por eminentes médicos de los USA ${ }^{13}$ que la agricultura derivada de la "revolución verde", esa que hoy es denominada "convencional", es cancerígena. ${ }^{14}$

El calentamiento global es responsable de la aparición de enfermedades anteriormente desconocidas en las regiones frías del planeta, vgr. los mosquitos, vectores de malaria, dengue y muchas otras enfermedades, amplían su hábitat debido al incremento global de la temperatura; el gusano barrenador, asimismo, invade Norteamérica y destruye cientos de hectáreas de bosques.

Asimismo, la expansión geográfica de la especie humana y, por ende, la cada vez mayor cercanía con múltiples especies animales, ha ocasionado la aparición de una importante variedad de enfermedades zoonóticas (Ébola, Virus del Nilo, Hendra, Gripe aviar, entre otras). ${ }^{15}$

La emergencia, en abril del 2009, de la "Gripe porcina" o "Influenza mexicana" es un claro ejemplo de epidemia antropogénica pues, tal y como muchos especialistas afirmaron, ${ }^{16}$ este virus es un derivado de las prácticas agroindustriales modernas. Los nuevos virus mutantes (AH5N1, AH3N2, $\mathrm{AH} 1 \mathrm{~N} 1)$ son un derivado directo de la manera como se realiza la agroindustria

\footnotetext{
${ }^{11}$ El Centro de Investigaciones en Geografía Ambiental de la UNAM informó recientemente que para el periodo 1976-2000 la tasa de deforestación fue del 0.43\% anual, es decir, 545 mil ha por año, cifra similar a la que ocupa el Estado de Aguascalientes (Flamenco, A.; Mas, J-F, "El desvanecimiento de los bosques en México", Boletín de la UNAM Campus Morelia No. 22, México, 2009, p. 3), cuestión también denunciada por Terence Pennington y José Sarukhán en la última edición de su Arboles Tropicales de México (UNAM/FCE, México, 2005, p. 16ss).

${ }^{12}$ The population bomb, Ballantine Books, New York, 1968.

${ }^{13}$ El President's Cancer Panel es dirigido por el Dr. LaSalle Leffall, oncólogo y profesor de Cirugía en la Howard University y por la Dra. Margaret Kripke, inmunóloga del M.D. Anderson Cancer Center de Houston.

14 "Traditionally, we reduce cancer risks through regular doctor visits, self-examinations and screenings such as mammograms. The President's Cancer Panel suggests other eye-opening steps as well, such as giving preference to organic food, checking radon levels in the home and microwaving food in glass containers rather than plastic. [...] Give preference to food grown without pesticides, chemical fertilizers and growth hormones" [los subrayados son nuestros], Lefall; Kripke 2010: ii.

${ }^{15}$ Quammen, D., "Contacto letal", National Geographic, Junio 2009, p. 3ss.

${ }^{16}$ Vide "Vincula José Sarukhan cambios ecológicos con nuevas enfermedades", Excélsior, 18 de mayo de 2009.
} 
moderna, esa donde los animales son hacinados en jaulas estrechas (y donde el contagio de todo tipo de enfermedades es una realidad tan cotidiana que para evitar los decesos masivos los agroindustriales no tienen otra posibilidad que administrarles cantidades ingentes de antibióticos) y donde el "libre pastoreo" es simplemente un sueño.

El cambio climático también ha producido una desregulación de los ciclos naturales, vgr. varias especies de pájaros ya no salen de sus huevos en el momento preciso en el cual la comunidad de orugas es floreciente, con la consecuente disminución de los primeros y aumento de las segundas, todo lo cual no deja de afectar negativamente a nuestra agricultura, entre muchos otros efectos (pues la creciente población de orugas no consumida por las aves no puede sino alimentarse de las plantas que encuentre, incluidos nuestros cultivos). $Y$ los cambios derivados del Calentamiento global son de una velocidad tal que múltiples ecosistemas de la tierra se encuentran en situación de riesgo grave. ${ }^{17}$

\section{El envenenamiento de la tierra}

Ha pasado medio siglo desde que Rachel Carson en su Silent spring intentó alertar a la humanidad respecto al daño que ocasionaría a los ecosistemas el uso masivo de pesticidas. Los venenos, bajo la forma de herbicidas, pesticidas y muchos otros productos químicos, que son vertidos en la tierra se encuentran incluso en las regiones más apartadas del globo pues el porcentaje de ellos que los cultivos absorben es simplemente ridículo. La mayor parte de tales venenos terminan en los cuerpos de agua y, por ende, afectan las cadenas tróficas.

El envenenamiento de la tierra se ha presentado, asimismo, en la muerte de miles de millones de abejas en las naciones desarrolladas, con la consecuente disminución en la polinización de los cultivos. ${ }^{18}$ La razón de tal disminución no es, como un informe inicial sostuvo, la presencia de un virus ("la gripe española de las abejas") que mermó gravemente a la población (hubo productores europeos que perdieron el $90 \%$ de sus enjambres) sino la mezcla de pesticidas elaborados por las grandes transnacionales (Monsanto, Syngenta, Dupont, Bayer, ente otras) que cotidianamente los agricultores emplean para atacar a las distintas plagas de sus cultivos. ${ }^{19}$ La empresa Monsanto, como nos relata

\footnotetext{
${ }^{17}$ Montaigne, F., "Marcas ecológicas", National Geographic, Septiembre 2004, p. 44.

${ }^{18} Y$ las abejas no son las únicas afectadas por los pesticidas. En el artículo "¿Dónde están las lombrices?", la Dra. Angeluz Olvera, del Centro de Investigación en Biotecnología de la Universidad Autónoma del Estado de Morelos, da cuenta de un curioso fenómeno: la desaparición de las lombrices de los suelos cultivables morelenses. Este acontecimiento no carece de importancia en la medida en que, como bien sabemos, las lombrices de tierra son elementos fundamentales para la aireación y, por ende, la fertilidad de la tierra. La ausencia de lombrices constituye un importante factor de la degradación de nuestros suelos. La razón de la desaparición de nuestras lombrices, nos indica la Dra. Olvera, es el uso masivo de plaguicidas organofosforados, los más comúnmente utilizados por nuestros campesinos... y también en muchos otros países del orbe. Cfr. Newman, M. C., M. A. Unger., Fundamentals of Ecotoxicology, CRC Press, Boca Ratón/London/New York/Washington, 2002, p. 3ss.

${ }^{19} \mathrm{Al}$ respecto es muy recomendable el estudio realizado por Fernando Bejarano, de la RAPAM (Red de Acción sobre Plaguicidas y alternativas en México) sobre los plaguicidas prohibidos en
} 
Marie Monique Robin (2008:84ss), se hizo tristemente famosa cuando debió reconocer, ante jurados americanos y europeos, como falsa la propaganda que presentaba su "Roundup", el herbicida más exitoso de todos los tiempos, al cual anunciaban como "100\% biodegradable", que "no dejaba residuos en el suelo" y "respetaba al medioambiente". Afirmaciones que, con el paso de los años, se demostraron, todas y cada una de ellas, absolutamente falsas.

En el 2007, el Dr. Alfonso Guadarrama (del CAPIFAC) ${ }^{20}$ informó del enorme porcentaje de bebés nacidos con malformaciones congénitas en el "Corredor hortiflorícola" del Estado de México (desde Tenancingo hasta Villa Guerrero). En esa región, un enorme $12 \%$ de los nacidos vivos presentan sea hidrocefalia, espina bífida, anoftalmia y demás trastornos congénitos derivados del uso de los plaguicidas. Y la razón de ello es muy simple: dado que las flores son aquello de lo cual se nutren los insectos, son increíblemente atractivas para ellos y, para defenderlas, los agricultores emplean cantidades enormes de pesticidas. ${ }^{21} \mathrm{~A}$ esto hay que agregar que, como dichos cultivos se realizan en invernaderos, la absorción cutánea de los pesticidas por los campesinos se potencia de manera alarmante. De tal manera generamos flores venenosas que no sólo matan a los insectos sino que ocasionan trastornos genéticos a nuestros hijos.

\section{La crisis energética mundial}

La humanidad globalizada moderna existe gracias a una fuente energética que explota como si fuese inagotable: el petróleo. El petróleo, una substancia que la naturaleza tardó millones de años en producir y que la humanidad conoce desde hace miles, se encuentra desde hace cuatro años en fase de declinación. ${ }^{22}$ Hemos construido toda una cultura gracias a sus ventajas energéticas, pero es un recurso no renovable y en decremento paulatino e irremediable. No está demasiado lejana la fecha en la que vamos a pagar los costos de nuestro dispendio y falta de previsión. La humanidad previa a la era del petróleo apenas superaba los 1000 millones de habitantes. Esa cifra, gracias al petróleo, se ha multiplicado por 7 en apenas dos siglos y, como antes indicamos, este 2011 alcanzaremos los 7 mil millones. ${ }^{23} \mathrm{Y}$ mientras la humanidad se triplicó en el Siglo XX, la demanda de agua, en el mismo siglo, se sextuplicó. $Y$ lo que es peor, los demógrafos esperan 9 mil millones de seres humanos para el 2045.

\footnotetext{
$\begin{array}{lllll}\text { muchos países pero aceptados éxico } & \end{array}$ (http://www.laneta.apc.org/emis/sustanci/plaguici/plagui.htm).

${ }_{20}^{20}$ Asociación ambientalista Guerreros verdes, 2007.

${ }^{21} \mathrm{Y}$ esto no es privativo de los floricultores. Como indica David Pimentel: "En promedio, las pérdidas que infringen los insectos a las cosechas han sido prácticamente multiplicadas por dos, pasando de $7 \%$ a $13 \%$ desde los años cuarenta, y ello a pesar de una multiplicación por diez de las cantidades de insecticida utilizados. Una vez que comenzamos a utilizarlos, es casi imposible renunciar a ellos, cualesquiera que sean los costos y los perjuicios, pues el suelo queda destruido, los parásitos se hacen más temibles, etc." (Scientific American, juin 1990: 7378).

${ }^{22}$ Cfr. el Informe 2008 de Colin Campbell en la ASPO (Association for the Study of Peak Oil and Gas).

${ }^{23}$ National Geographic, enero 2011, p. 10ss.
} 
El mundo en el que vivimos existe gracias al petróleo. Con petróleo no sólo nos transportamos y se genera la mayoría de nuestra energía eléctrica, son petróleo nuestros plásticos, el gas de nuestras estufas y calentadores, gran cantidad de nuestras telas y hasta las suelas de nuestros zapatos. También con petróleo se transportan las mercancías que consumimos y se fertilizan, siembran y cosechan nuestros campos. El hombre moderno prácticamente come gracias al petróleo. Es por tal razón que su eventual desaparición tendrá un impacto incalculable. Los yacimientos de petróleo que en nuestros días se descubren son cada vez más pobres o inaccesibles, lo cual implica que su explotación será cada vez menos rentable. Como señaló el Dr. Buenfil Friedman, de la Universidad de Florida, el petróleo barato y fácil de extraer ya se consumió. ${ }^{24}$

Fue el geofísico estadunidense Marion King Hubbert, entonces director del laboratorio de prospecciones de Shell, el que definió al "pico del petróleo" como el momento de máxima producción de un yacimiento petrolero y predijo correctamente, en 1956, la ocurrencia de dicho pico en los yacimientos de los USA en 1970. Siguiendo la misma metodología los Dres. Colin J. Campbell ${ }^{25}$ y Kjell Aleklett de la ASPO (siglas en inglés de la Asociación para el estudio del pico del petróleo y el gas) han indicado que dicha cumbre la alcanzó la humanidad en el $2008,{ }^{26}$ es decir, que a partir de esa fecha la cantidad de petróleo que se extraerá de los yacimientos en todo el mundo empezará a declinar. Prácticamente todos los países productores han reconocido haber alcanzado su Pico de producción petrolera (USA en 1970, Indonesia, Egipto y Venezuela en 1997, Argentina en 1998, Noruega en 2001, Irán en 2003 y México en 2005, sólo por mencionar algunos). A pesar de que los yacimientos "viejos" declinan y los recién descubiertos son pobres, la humanidad, ciega, sigue consumiendo petróleo de manera acelerada, obligando a los países productores a la explotación desmedida de sus yacimientos y a intentar explotar otros increíblemente riesgosos como demostró el reciente derrame de la plataforma Deep Water Horizon de British Petroleum en las aguas profundas del Golfo de México. Actualmente, por cada barril de petróleo recién descubierto se consumen cinco. La disminución del recurso, aunada al aumento de la demanda ha conducido al incremento del precio del petróleo ${ }^{27}$ en los años inmediatamente recientes. Pero ello no ha frenado la inercia del mundo neoliberal. Henri Prevot indica en su libro Trop de pétrole ${ }^{28}$ que aún contamos con suficiente petróleo en la tierra para acabar con nuestra atmósfera, es decir, que constituye un grave error continuar arrojando tan enormes cantidades de dióxido de carbono, metano y otros gases de efecto

\footnotetext{
24 Buenfil Friedman, F., "Cuando se acabe el petróleo", 2005 (http://www.rebelion.org/docs/22065.pdf).

25 Autor, junto con Jean Laherrère, del artículo, polémico en aquellos años, evidente en los nuestros, "The end of cheap oil", Scientific American, March 1988.

${ }^{26} \mathrm{http}: / /$ www.hubbretpeak.com/Hubert/

${ }^{27}$ A mediados del 2008 el WTI alcanzó la enorme suma de 147 USDlls por barril (McKibben, B., "Energía del futuro", National Geographic, edición especial, 2009, p. 24) y en el 2011 fluctúa alrededor de los 100 USDIls por barril (cuando hace apenas 40 años se vendía a 10 USDIls el barril).

${ }^{28}$ Prevot, H., Trop de pétrole, Seuil, Paris, 2007.
} 
invernadero a la misma. En el mismo tenor, Mario Molina ${ }^{29}$ afirmó durante los debates sobre la Reforma energética mexicana, el 27 de mayo del 2008, que "la atmósfera se nos acabará antes que el petróleo". 30

En muchos países se continua quemando petróleo hasta para producir electricidad, en vez de construir plantas de generación eléctrica a partir de la energía renovable (solar, eólica, geotérmica, maremotríz, etc.). No sobra indicar que la energía nuclear tampoco es una opción. Las catástrofes de la Planta nuclear de Three Mile Island, Chernobyl y, recientemente, Fukushima, nos muestran que el riesgo que conlleva la energía nuclear es demasiado grande y que, sinceramente, no vale la pena correrlo cuando es cada vez más rentable la energía renovable.

El futuro de la humanidad, finalmente, se encuentra en vilo pues las últimas COP (Conferencias de las Partes), las más recientes realizadas en Copenhage (2009) y Cancún (2010), han mostrado que las naciones industrializadas más contaminantes, y las empresas que realmente las dirigen, no están dispuestas a reducir sus emisiones de gases de efecto invernadero. $Y$ muchas otras naciones toman eso como pretexto para no hacer prácticamente nada. $Y$ no sobra agregar que el consumismo de cada uno de los ciudadanos del mundo nos hace cómplices de las malas decisiones de tales gobiernos y empresas depredadoras.

\section{La crisis financiera y alimentaria}

La humanidad globalizada ha entrado en un periodo de franca recesión derivada de una crisis financiera que, desgraciadamente, afectará, como siempre, primero a los más pobres. ${ }^{31}$ Ya no sólo el calentamiento global será el responsable de la reducción de la producción de alimentos con el consecuente aumento del costo de los mismos, ${ }^{32}$ hay que sumarle ahora la crisis financiera.

El calentamiento global, aunado o no al fenómeno de "El niño", genera sequías y pérdidas de la productividad agrícola en muchos lugares de la tierra. Por ejemplo, según el Anexo estadístico del Tercer informe de Gobierno del

\footnotetext{
${ }^{29}$ Co-receptor, junto con Paul Crutzen y Sherwood Rowland, del Nobel de Química en 1995 por sus estudios sobre los terribles efectos de los clorofluorocarbonos (CFC) en la capa de ozono de la tierra.

${ }^{30} \mathrm{http}: / / \mathrm{www}$. centromariomolina.org/noticias.php?id=43

${ }^{31}$ En la Convención Marco de la ONU sobre Cambio climático, realizada a finales de marzo del 2011, el Subdirector general de Recursos Naturales de la FAO, Alexandre Müller informó que los efectos de "inicio lento" del Cambio climático producirán graves daños que pondrán en dificultades a los ecosistemas para proporcionar los servicios necesarios para la agricultura, con consecuencias "potencialmente catastróficas" para la seguridad alimentaria en el periodo 2050-2100. Cfr. Teorema ambiental, 1 de abril 2011.

${ }^{32}$ Tal y como refiere Joel K. Bourne, ("El fin de la abundancia", National Geographic, juin 2009), del 2005 al 2008 se triplicó, a nivel mundial, el precio del maíz y el trigo y se quintuplicó el del arroz, incrementando en 75 millones la cifra de los aquejados por pobreza extrema. El calentamiento global es responsable del descenso de la producción de cereales a nivel mundial, y eso solamente con el incremento del $0.8^{\circ} \mathrm{C}$ en la temperatura media del mar y con $385 p p m$ de $\mathrm{CO} 2$ en la atmósfera. Y la cada vez mayor cantidad de gases de efecto invernadero que las industrias de las naciones desarrolladas y emergentes arrojarán a la atmósfera en los años venideros no hará sino agravar el problema.
} 
Presidente de México, en los últimos 10 años el déficit de la balanza agropecuaria mexicana se ha incrementado de manera alarmante: de 122 millones de USDlls en el 2000 a 3,972 millones de la misma moneda en el 2009. ${ }^{33}$ Sin embargo, como bien señala David Barkin, la crisis alimentaria mexicana podría resolverse de manera inmediata, simplemente destinando al consumo humano la enorme cantidad de granos que se utilizan para engordar ganado... aunque no se aprecia que nuestras autoridades se percaten de esa posibilidad que, por cierto, correctamente aplicada (alimentándonos con la dieta básica de los aztecas: maíz, frijol y chile) podría mejorar marcadamente la salud de los mexicanos.

En la XXX Conferencia Regional de la Organización de las Naciones Unidas para la Agricultura y la Alimentación (FAO) realizada en abril del 2008 en Brasilia, el Director general de la FAO, Jacques Diouf, informó que la crisis derivada del incremento de los precios de los alimentos en el mundo será prolongada. Ello es debido al incremento en los precios del petróleo y de los fertilizantes (que aumentaron de precio en un 58\% sólo en 2007). Los USA, además, han decidido utilizar su sobreproducción de granos ya no en ayuda humanitaria sino en la producción de biocombustibles. A pesar de que el mundo produce una enorme cantidad de granos, tal y como informó Olivier de Schutter, relator especial de la ONU sobre el derecho a la alimentación, una sexta parte de la humanidad padece hambre crónica a causa de la especulación financiera y la falta de apoyo a los pequeños productores. ${ }^{34}$ En Latinoamérica, Guatemala, Nicaragua y El Salvador fueron los primeros en ver incrementar el hambre en sus naciones, debido a que sus economías no logran producir los alimentos que requieren, como consecuencia del azote de huracanes y sequías. $Y$ las consecuencias son evidentes: nueve millones de niños menores de cinco años están desnutridos en Latinoamérica (de 30 millones que padecen hambre). En Guatemala, Honduras y Bolivia, entre $27 \%$ y $49 \%$ de los niños padecen desnutrición crónica, de acuerdo a cifras de la ONU.

Y en este triste panorama, la ciencia y la tecnología moderna no carecen de responsabilidad, la ciencia y la tecnología son pieza fundamental en la generación de la catástrofe antes mencionada debido a un problema de método, uno que comparten con el sentido común. Estudiémoslo con cuidado.

\section{Un problema de método}

Gracias a los trabajos de la epistemología sabemos que el método de la ciencia establece una relación unívoca entre el investigador y su objeto, método que, indican, permite obtener conocimientos fiables y "objetivos".

En buena parte de las diversas filosofías, por el contrario, históricamente se ha reconocido otro método como propio: la introspección, esa que Heráclito definía en su fragmento 101 de la siguiente manera: "me busqué y rebusqué a mí mismo". Dicho principio, desde mi punto de vista, también sostiene los

\footnotetext{
${ }^{33}$ La Jornada, 6.10. 2009, p. 25.

${ }^{34}$ La Jornada, 13.09.2009, p. 29.
} 
esfuerzos hegelianos o heideggerianos... ¿no culmina la Fenomenología del espíritu de Hegel con la certeza de constituir una conciencia que se sabe "toda realidad"?, asimismo, ¿no inició el maestro de Messkirch su búsqueda del sentido del ser a partir de preguntarse sobre las cualidades del Dasein, es decir, sobre ese ente "que soy en cada caso yo mismo"? ${ }^{35}$ La introspección es viable como método en la medida de que el pensador se sabe uno con el otro (Mitsein) y el todo (In-der-Welt-sein) ${ }^{36}$ La ontología no podría ser posible sin dicha claridad.

Es por todo esto que Dany-Robert Dufour, considera que es una especie de iluminación, derivada de la introspección, la que produce un filósofo. ${ }^{37}$

Pero la introspección no es un método que sirva al científico. Es por ello que es conveniente revisar el que debió construir el psicoanálisis para aproximarse a su objeto.

\section{El peculiar método psicoanalítico}

Es ampliamente conocido que cuando Freud se refería a los orígenes de su práctica no reconocía fuentes filosóficas sino que indicaba un dato preciso: el sueño ocurrido en la noche del 23 al 24 de julio de 1895, ese denominado por la tradición: el sueño de la inyección aplicada a Irma, ${ }^{38}$ sueño que Freud mismo pudo leer de manera suficientemente convincente para generalizar la hipótesis, luego desplegada en la Traumdeutung: "el sueño es una realización de deseos". 39

Gracias al análisis de dicho sueño, el cual ya he comentado con detalle, ${ }^{40}$ Freud pudo percatarse de la existencia de una instancia diferente a su yo, una que denominó "inconsciente" y que le permitía entender la presencia de deseos incompatibles con su moral, con su conciencia. Freud, no consideró a su sueño, como hacían los neurólogos de la época, como una "actividad errática del cerebro", sino que prefirió tomarlo como un fenómeno cargado de sentido y se abocó a descifrarlo. Acto seguido inició el análisis: divide al sueño en escenas y asocia respecto a los elementos presentes en cada una de ellas, dejándose llevar por su pensamiento y tratando de no omitir detalle alguno. Al final del proceso Freud contaba con un texto mucho más amplio que le obligaba a reconocer un deseo reprimido por él mismo, un deseo que sólo a

\footnotetext{
${ }^{35}$ No olvidemos que, hacia el final de su vida, Heidegger prefería hablar de "camino" (en griego "odos", raíz del vocablo "met-odos") para nombrar su tarea.

${ }^{36}$ En la traducción de José Gaos del Sein und Zeit heideggeriano, respectivamente, "Ser con otros" y "Ser-en-el-mundo".

${ }^{37}$ Dufour, D-R, Les mystères de la trinité, Gallimard, Paris, 1990, p .15. Vide también: Tamayo, L., El discipulado en la formación del psicoanalista, ICM/CIDHEM, México, 2004, p. 79.

${ }^{38}$ Sigmund Freud, "Traum vom 23./24. Juli 1895" en Die Traumdeutung, (Fischer, Frankfurt am Main/Hamburg, 1964, pp. 98-109).

39 "Der Traum ist eine Wunscherfüllung", ibidem, pp. 110 ss.

40 Un primera versión de una parte de este apartado fue publicado en la Revista de la Universidad, UNAM, México, noviembre de 2003. Respecto al sueño referido existen muchos otros estudios abocados al tema (Anzieu, Grinstein, Schur, Erikson, Lacan y Hernández García) para mencionar sólo a los más importantes.
} 
contramano admitía y cuyo rechazo de su parte era, para él, una prueba más de su validez. Y eso que Freud descubría se lo comunicaba, por vía epistolar, a su amigo berlinés, al otorrinolaringólogo y sexólogo aficionado Wilhelm Fliess, quien le contestaba (no sabemos qué, su correspondencia está perdida) lo necesario, y con el tino suficiente, para que Freud siguiera escribiéndole.

Dicho en términos claros, en esa situación tenemos a un Freud que se busca y se rebusca a sí mismo ${ }^{41}$ ante otro con el fin de encontrar el sentido de su sueño. Freud no estudiaba un objeto externo (como pretende el método científico), sino que lidiaba con una parte, oscura y enigmática, de sí mismo, con una parte de su subjetividad reprimida. Freud no era un sujeto que investigaba un objeto sino un sujeto que se miraba a sí ante otro.

Como se puede apreciar en el modelo epistémico del psicoanálisis se deja atrás el esquema que las ciencias utilizan para pensar la relación con su objeto:

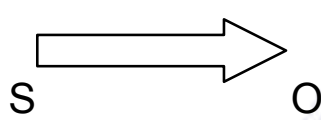

Y también el método introspectivo:

$\mathrm{S} / \mathrm{O}$

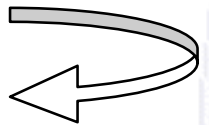

Para establecer otro método:

$\mathrm{S} / \mathrm{O}$

$$
\text { Otro (analista) }
$$

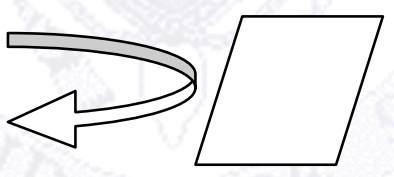

En dicho método el sujeto (el analizante) se investiga a sí mismo gracias a la pantalla de la transferencia que constituye el analista.

En el psicoanálisis no se deja fuera al sujeto (como en la ciencia, que al elidirlo pretende restarle importancia), tampoco parte de la unidad con el otro y el mundo (como en la filosofía) sino que se trata de una investigación del analizante sobre sí mismo ante otro, la cual lo conduce a modificar la propia vida y, al final, a generar un analista. $Y$ analista es aquél $-y$ esto hay que decirlo con claridad- que ha cursado hasta el fin su análisis, descubriendo en tal experiencia la existencia de procesos inconscientes propios y por ello comunes; analista es aquél que ha establecido un compromiso con la verdad, con su verdad, y que se aboca a su libertad —entendida no como el liberum

\footnotetext{
${ }^{41}$ A la manera de Heráclito, como ya indicamos.
} 
arbitrium o "capacidad electora" sino como lo que Heidegger define en el $\S 74$ de Ser y el tiempo como la "asunción de la tradición heredada".

En el psicoanálisis, lo reitero, el analista no opera como un sujeto que estudia a un objeto "exterior" —el paciente-, ni tampoco haciendo mera introspección (el, tan criticado por Freud, "autoanálisis") sino propiciando un espacio donde el impaciente analizante se estudia a sí mismo, en tanto "sujetobjeto", ante ese Otro denominado "analista".

El psicoanálisis es un espacio en el cual el analizante se pregunta por el sentido de su vida, por su ser. En el diván aparecen, "aterrizados", los grandes problemas filosóficos y es ahí donde encuentran solución, en acto, dichos enigmas.

El método descubierto por el psicoanálisis evita que el objeto sea considerado ajeno. Tal y como enseña Jacques Lacan, el objeto del psicoanálisis está en relación moebiana con su sujeto, es decir, que se encuentra en un adentroafuera. $^{42}$

El objeto, en el psicoanálisis es consustancial con su sujeto y ello impide una escisión que permitió a la ciencia carecer de principio precautorio.

Si el objeto, la naturaleza, me es consustancial, si no está simplemente afuera sino en un "adentroafuera", entonces no puedo sino preocuparme por los efectos que pueda tener mi actividad en él. Cuidarlo es cuidarme, respetarlo es respetarme.

Pero la ciencia y la tecnología, que desconocen o deliberadamente reprueban el método psicoanalítico, han descuidado un vínculo con la naturaleza que debía ser más "responsable", para retomar los términos de Jonas. ${ }^{43} \mathrm{Y}$ ello ha contribuido en gran medida a la degradación del mundo.

\section{La responsabilidad de la ciencia y la tecnología}

Desde hace ya varias décadas Ulrich Beck hablaba de la "sociedad del riesgo" para nombrar aquella en la cual vivimos. En su estudio La megamachine, Serge Latouche nos alerta al respecto:

El consumo de pescados y mariscos se convirtió en una experiencia de alto riesgo. El atún rojo del mediterráneo se ha vuelto sospechoso de estar saturado de mercurio, los mejillones de España tienen la reputación de arriesgarnos a contraer la hepatitis viral, etc. La agricultura, en efecto, utiliza todo un arsenal químico: hormonas, antibióticos, biocidas (insecticidas, herbicidas, nematocidas, fungicidas y rodenticidas) cuyos residuos se

\footnotetext{
${ }^{42}$ Tamayo, L., Del síntoma al acto, UAQ, México, 2001, pp. 31s.

43 Jonas, H., El principio de responsabilidad: ensayo de una ética para la civilización tecnológica, Herder, Madrid, 1995, p. 15. Cfr. también Echeverría, J., "El principio de responsabilidad de Hans Jonas: ensayo de una axiología para la tecnociencia" en Riechmann, J. (Coord.), Perdurar en un planeta habitable,Icaria/CiMA, Barcelona, 2006, p. 255ss.
} 
encuentran en los productos alimenticios. Según un bioquímico de la Universidad de Estocolmo, el Instituto Sueco de Salud Pública estableció que la leche humana contiene, en promedio, 0.117 partes por millón de DDT u otros compuestos similares. Eso significa que un niño alimentado con el pecho absorbe una cantidad de DDT y otros compuestos superior en un $70 \%$ al máximo reconocido actualmente como tolerable [De Closets, 1970, p. 280]. A eso se añaden los productos presentes en las preparaciones industriales: emulsificantes, conservadores, antioxidantes. "El agua que bebemos -escribe Edouard Goldsmith - está contaminada con nitratos, metales pesados y compuestos orgánicos de síntesis - pesticidas, por ejemplo- que ningún procedimiento comercial ni tratamiento de purificación suprimen completamente. El aire que respiramos está contaminado con el plomo de la gasolina, las partículas de amianto y cadmio de las balatas de los frenos, por el óxido de carbono y los óxidos de nitrógeno de los gases de escape, por el anhídrido sulfuroso de las humaredas de gasolina, por el yodo radioactivo, el cesio y una enorme cantidad de radionucleótidos provenientes de las instalaciones nucleares en funciones" [Goldsmith, 1994, p. 262]. Y ahora sabemos, gracias al informe del profesor Belpomme [2004], que todo eso es altamente cancerígeno. $^{44}$

Y no sólo Latouche y Beck dan el grito de alerta, Ellul, Morin, Asimov, McEwan, Gorz, Illich, Galeano y Lovelock, entre muchos otros científicos y pensadores, han intentado que la humanidad despierte y cambie el futuro en el presente. La mayoría de la gente desgraciadamente, entretanto, prefiere no pensar en las consecuencias de sus actos y actúa como si el crecimiento infinito fuese siempre posible, como si siempre hubiese más para todos, como si los recursos de la tierra fueran infinitos, como si la humanidad pudiese no preocuparse por el daño que hace a la tierra.

Y la investigación científica, en su afán por quedar bien con las grandes corporaciones de todo tipo (desde las militares hasta las espaciales) ha contribuido en gran medida a ese oscuro panorama:

En los Estados Unidos, "El país que desde el comienzo del siglo da el tono, el presupuesto de la investigación se repartía, en 1969, de la siguiente manera: la mitad para las armas, un cuarto para el espacio, 12\% para el átomo. Quedaba, para el bien de la humanidad, las necesidades prácticas, el confort y la salud, solo un 13\%" [Bonnot, 1976, p. 106]. En 1993, también en los Estados Unidos, 43 mil millones de dólares -es decir veintiún veces el presupuesto de las Naciones Unidas - son consagrados a la investigación militar. Un millón de investigadores en el mundo trabajan para fines militares [Lavielle, 1993, 1994]. Francia gasta, en promedio, tres veces más dinero para investigación militar y espacial que para investigaciones sobre la calidad de la vida humana [de Closets, 1970, p. 65]. En 1993, todavía eran consagrados a la investigación espacial 668 millones. $^{45}$

\footnotetext{
${ }^{44}$ Latouche, S., La mégamachine, La découverte/ MAUSS, Paris, 2004, p. 84.

45 Ibidem, p. 96.
} 
Nuestros científicos, tal y como denuncia Latouche, mayoritariamente en el mundo, se han convertido en colaboradores de las peores corporaciones y, al hacerlo, en instrumentos de la depredación. Ya no puede ser negado que cada vez que un científico o tecnólogo, por ejemplo, colabora en el mejoramiento del percutor de un arma de fuego se convierte, ipso facto, en cómplice de los asesinos que darán uso a las armas por él mejoradas.

Afortunadamente no todos los científicos y tecnólogos del mundo han caído en tan macabro juego. Han sido también bastantes los que han ofrecido alternativas conviviales y tecnológicas acordes al cuidado de la naturaleza. Gracias a ello, la crisis futura (derivada del cambio climático global, el fin de la era del petróleo barato y la crisis financiera generalizada) puede ser mitigada. $Y$ para lograrlo son menester acciones en muy diversos ámbitos.

\section{Mitigando los efectos}

I. El cambio en la concepción del mundo.

Para aminorar los efectos de la catástrofe ambiental es necesario, en primer lugar, que nuestros científicos y tecnólogos, así como todos los ciudadanos del mundo, apreciemos que nuestros actos tienen consecuencias, que en la medida que cometamos el error ontológico de considerar al otro y el mundo como ajenos sólo contribuimos a la degradación de nuestra propia casa y el asesinato interminable. Necesitamos que nuestros científicos y tecnólogos adquieran el principio de responsabilidad y dejen de colaborar con las corporaciones ecocidas. Necesitamos asimismo que los ciudadanos participen del boicot a los productos de las corporaciones ecocidas actualmente existentes.

\section{La sustentabilidad en la vivienda, la escuela y la región}

En muchos lugares del mundo existen jardines familiares. Si logramos convencer a la población de producir hortalizas y frutales, los cuales sean cultivados orgánicamente (sin fertilizantes ni pesticidas inorgánicos), se incrementará nuestra producción de alimentos de manera significativa. Para lograrlo es imprescindible construir una cisterna de buen tamaño pues el cambio climático hará cada vez más erráticas las lluvias.

Asimismo, en las regiones de la tierra con buen asoleamiento, es factible generar electricidad para los hogares e industrias gracias a la energía solar. El potencial geotérmico, maremotríz y eólico del mundo, asimismo, es otra opción valiosa y factible.

Las escuelas, asimismo, pueden convertirse en los espacios demostrativos de las tecnologías ecoamigables (arquitectura bioclimática, viveros orgánicos, energía alternativa, biodigestores, separación de residuos, producción de composta, etc.). Para lograrlo es menester primero formar a los directivos y profesores en los principios básicos de la sustentabilidad, pues ellos son los 
comunicadores idóneos de sus comunidades. Hay que promover, incluso, la agricultura urbana aplicando buenas prácticas agrícolas.

\section{Sustentabilidad en el transporte}

El mundo requiere convertir a cada automovilista en un peatón o en un ciclista. Una red de trenes y/o metrobuses (como los que existen en Europa o los que atraviesan la Curitiba brasileña) podría permitir a los habitantes de las grandes ciudades trasladarse sin necesidad de embotellarse en sus calles. Y si en tales autobuses existiesen racks que permitiesen colocar la bicicleta, el transporte, incluso en las grandes ciudades, podría ser muy eficiente.

\section{Sustentabilidad en el manejo de los residuos}

Cuando se cuenta con voluntad política, se puede construir la infraestructura adecuada para el manejo sustentable de los desechos (plantas de separación de residuos, industrias recicladoras, composteros municipales), lo cual, aunado a un programa amplio de formación ciudadana sobre la separación de sus residuos, permite a las naciones no sólo generar recursos por la venta de composta (derivada de la enorme cantidad de residuos orgánicos que el mundo produce) sino de otras materias primas (papel, aluminio, plástico, vidrio, etc.). De esta manera podría el mundo aspirar a un programa de basura cero, tal y como han logrado algunas ciudades de las naciones más desarrolladas.

\section{Sustentabilidad en la paternidad.}

Nuestro mundo requiere establecer programas de paternidad responsable y otros programas de planificación familiar. Cuando la población crece sin control la vida humana llega a ser despreciable, lo cual favorece el crimen y la explotación. Responsabilizarse de los hijos requiere, en primer término, vigilar que su número sea el que podemos educar y mantener correctamente... y eso debe informarse y fomentarse con programas poblacionales estatales.

\section{Sustentabilidad en el ámbito técnico}

Lograr los cambios que el mundo requiere implica contar con técnicos conscientes y especializados en el desarrollo sustentable, con principio de responsabilidad y formados en el ACV (Análisis del Ciclo de Vida) de los productos. Necesitamos, asimismo, las escuelas que los formen. También son menester las empresas que se aboquen a dotar los insumos para su trabajo. Los Estados debe formar a tales técnicos y apoyar a tales empresas. $Y$ todo ello requiere de una férrea voluntad política.

\section{Sustentabilidad y convivencialidad}

El mundo también requiere construir comunidades donde la convivialidad ${ }^{46}$ renazca. Apagar la enajenante televisión permite que reaparezca el deseo de

${ }^{46}$ Cfr. Illich, I., "La convivencialidad", en Obras reunidas I, FCE, México, 2005, p. 367-530. 
encontrarse con amigos, de acercarse a los vecinos para resolver los problemas comunes. Si nos permitimos cerrar la "ventana al mundo" podremos abrir la ventana a nuestro vecindario y hacer nuestros los problemas de nuestra comunidad.

\section{Conclusiones}

La especie humana moderna no acabará con la vida, eso es demasiado incluso para ella, sólo acabará con el ambiente que le es propicio. Cuando la humanidad haya aumentado la temperatura media del mar en sólo 6 grados centígrados, ya no será posible la vida para ella por la gran cantidad de fenómenos hidrometeorológicos que se generarían, pero cucarachas, cactos y muchas otras especies seguramente gozarán del nuevo hábitat, tal y como ocurrió cuando la desaparición de los dinosaurios.

En la medida en que nuestro consumismo desenfrenado, nuestro desdén respecto a la generación de basura y demás actividades ecocidas, se presenten sin control ni regulación, el mundo humano se encaminará a una catástrofe derivada de un error ontológico: haber olvidado que el otro y el mundo nos son consustanciales, que las demás especies del mundo merecen todo nuestro respeto y que la naturaleza tiene un equilibrio muy delicado que, al romperse, ocasiona efectos muchas veces insospechados y fatales para toda la biosfera.

No es imposible recuperar la claridad de conciencia respecto a la unidad hombre-mundo, ${ }^{47}$ pero ello implica una tarea educativa continua y dedicada, implica educadores, autoridades políticas y técnicos conscientes y comprometidos. También requiere una ciudadanía y una comunidad científica muy comprometida en la solución del problema.

Afortunadamente cada vez contamos con más científicos (como los de la UCS americana, la CiMa española o la UCCS mexicana, entre muchas otras $)^{48}$ que tienen bastante claro el problema y realizan acciones para mitigarlo. Son ellos los que nos permiten pensar que la humanidad aún tiene algún futuro.

Cuernavaca, Morelos, 6 de abril de 2011

\footnotetext{
${ }^{47}$ Aunque, no sobra decirlo, no tenemos mucho tiempo. El 23 de noviembre de 2008, lan McEwan, en una entrevista que sostuvo para El País, que, de no hacer nada para evitar el deterioro ambiental mundial, el punto de no retorno, es decir, ese que una vez rebasado implicaría la imposibilidad para detener la destrucción de la biosfera, ocurrirá en el 2016.

${ }^{48}$ La Union of Concerned Scientists (UCS) fue fundada en el MIT de Cambridge en 1969; el grupo Científicos por el Medio Ambiente (CiMA) fue fundado en el 2003 en Barcelona y es actualmente dirigido por Javier Benayas; la Unión de Científicos comprometidos con la Sociedad (UCCS) fue lanzado en México en el 2006 y es dirigida actualmente por Elena Álvarez Buylla.
} 